\title{
Application of Conjoint Analysis in Establishing Aviation Fuel Attributes for Air Travel Industries
}

\author{
Karla Ishra S. Bassig, Hazeline A. Silverio \\ and Venusmar C. Quevedo \\ Industrial Engineering Department, Adamson University, Manila, Philippines 1000 \\ E-mail: $\{$ karla.ishra.bassig, hazeline.silverio\}@adamson.edu.ph; \\ vcquevedo@gmail.com
}

Received 15 October 2016; Accepted 17 November 2016;

Publication 14 February 2017

\begin{abstract}
With oil being a non-renewable energy, buyers of aviation fuel are more inclined to purchase Jet-A1 from oil companies that offer the best jet fuel. Aviation fuel has the same content even when purchased halfway across the world. Although price is an apparent factor that airlines consider when deciding which oil company to choose for as a supplier, there are ambiguous factors that need to be established so that continuous product development can be made by the aviation fuel organizations. This study used conjoint analysis as a tool to establish the attributes considered by airlines in deciding which oil company best meet their needs. As a result, the following six attributes of aviation fuel were identified: availability, price, accessibility, manpower, equipment and facilities and fuel quality and safety. The results indicate that fuel quality has the greatest influence on the respondents' purchasing intentions, followed by price, availability, equipment and facilities, and accessibility. Manpower was the least important attribute with regard to the airlines' buying intention.
\end{abstract}

Keywords: Conjoint analysis, Aviation fuel, Purchasing intention, Consumer preference, Part-worth.

Journal of Industrial Engineering and Management Science, Vol. 1, 15-32.

doi: 10.13052/jiems2446-1822.2017.002

(c) 2017 River Publishers. All rights reserved. 


\section{Introduction}

Jet Fuel (Jet A-1) is produced only by the three-major Oil Company in the Philippines namely, Petron, Shell and Chevron. Jet Fuel from these companies are then stored under the supervision of Joint Oil Companies Aviation-Fuel Storage Plant (JOCASP). Despite the different companies that supply jet fuel, the reality is that they all provide the same oil to different airlines. A bidding system is used to help decide what oil company is approached when it comes to their jet fuel supply and consider factors, aside from price and availability, in making the oil supplier choice. These are uncertain factors that are expected to be identified as the researchers use conjoint analysis as an analytical tool for the aviation fuel suppliers; this will help them improve on their product management and service based on the set of criteria from the conjoint analysis that the researchers are seeking to establish. With over 33 airlines operating in the local aircraft industry, it's an unexpected reality that Philippines have only one source of jet turbine engine fuel (Jet A-1) of which all the aviation oil companies are the beneficiary. By means of a bidding system, the crude oil trade commences between the local airlines and the aviation oil depots. While these aviation oil entities supply the same kind of fuel, there are uncertainties as to why airlines change their decisions on their fuel supplier. This can come as an opportunity for the oil companies and other airlines but without a doubt, difficulties will emerge along with the seeming opportunities because of the unsystematic bidding approach both parties are currently bounded by.

The objectives of the study are as follows: (1) Identify the key attributes that are taken into consideration by airlines operating locally in assessing viable jet turbine engine fuel supply using conjoint analysis. (2) Establish a decision criteria and metrics based on the key attributes that heavily influences the airline organizations' purchasing intention. (3) Develop an integrated assessment of the jet fuel service and define an approach that will enable the local jet fuel suppliers to optimally provide the needs of the airlines operating in the Philippines. This study to help both the airline organizations and aviation fuel companies in improving their decisions and product management.

\section{Review of Related Literature and Studies}

\subsection{Conjoint Analysis}

Conjoint analysis helps in recognizing the trade-offs the market will make and then applying the newly acquired market knowledge to the organization's revenue, profit or share objective. Conjoint analysis has been effectively 
functional in many industries, such as financial services, health care, real estate, air travel, electronics, computers and smart phones. Because conjoint analysis helps in comprehending a market's preferences, it is applicable to a variety of difficult aspects of the job, including competitive positioning, pricing, product line analysis, product development, segmentation and resource allocation; a conjoint analysis done right is impactful. (Halme \& Kallio, 2014). Basically, conjoint analysis is a set of market research techniques that measures the value the market places on each feature of a product and predicts the value of any combination of features. With conjoint analysis, one must ask questions that force respondents to make trade-offs among features, determine the value they place on each feature based on the trade-offs they make and simulate how the market reacts to various feature trade-offs you are considering. Extensive concentration has been given to this technique both in the field of the academe and industry to quantify preferences through utility trade-offs among products and services particularly. (Lee \& Kuo, 1998).

\subsection{Decision Trade-Off}

Trade-offs is the heart of product management. Whether the objective is to increase the market share, profit margin or revenue, the deciding person makes trade-offs - quality vs. cost, time to market vs. breadth of features, richness of the offering vs. ease of use, etc. Decision trade-off involves making a choice between one quality and aspect of an entity to gain something in return of another quality or entity of an entity. More particularly, trade-off decisions require a balanced bearing of which when one commodity increases, its equivalent entity must decrease. A trade-off decision generally requires the deciding person to have full comprehension of both the advantage and disadvantage of a specific option. (Lee \& Kuo, 1998).

\subsection{Preferences}

There are different types of preferences, preferences based on scenario, object preference, and model preference. Experienced customers expect that the options and choices currently available will lead to changes in their preference (Yanoff \& Hansson, 2009). Potential customers' actions will differ according to what they want, and therefore the central objects and scenarios of their preference will sway their decisions. How logically preferences are connected to each other makes them rational or true based, as well as all of the available and related information (Egonsson, 2007). Consumer preference is a make or break factor associated to whether a purchase will be made or not, and, 
if made, which specific item will be chosen (Novemsky, Dhar, Schwarz, \& Simonson, 2007).

\subsection{Purchase Intention}

Bendall-Lyon and Power (2004) asserted that customers judge the performance outcomes of using a product/service and then use this information to form their own succeeding expectations, as well as relying on the experiences of others through word-of-mouth. Behavioral intention can be divided into two categories: economic and social, as further studied by Bendall Lyon and Power (2004). Economic behavioral intentions came from activities repeated from their purchase behavior, while social behavioral intentions are those that are based in customers' complaints and engaging in word-of-mouth communication. Behavioral intention is an indication of a person's readiness to perform a behavior (Bergkvist \& Rossiter, 2008; Fishbein \& Ajzen, 2010), and the relative contributions of attitudes, perceived norms and perceived behavioral control with regard to a specific intention are expected to vary from one person to another. (Wu, Liao, \& Chatwuthikrai, 2014).

\subsection{Purchasing and Procurement}

Purchasing refers to the acquisition of goods and services of a business organization in order to meet the organizational goals and objectives. Though there are several organizations that attempt to set standards in the purchasing process, processes can vary greatly between organizations. The word purchasing is not used interchangeably with the word procurement, since procurement typically includes expediting, supplier quality, and traffic and logistics (T\&L). (Chand, Satyanarayana, \& Plant, 2013). Specifically, procurement involves the process of acquiring goods, works and services, covering both acquisitions from third parties and from in-house providers. This process starts from the identification of the needs, through to the end of a services contracts or the end of the useful life of an asset.

\section{Methodology}

\subsection{Research Design}

The purpose of this study is to identify the attributes of aviation fuel that affect the purchasing intentions of air travel organizations. Conjoint analysis was used to measure the potential customer preferences for Jet-A1. Conjoint 
analysis is widely used as a marketing tool to explore consumer preferences since it was first initiated. Conjoint analysis requires respondents to rate different scenarios with varying combinations of attribute levels. In this study, combinations of the fuel attributes were made into scenarios. Moreover, conjoint analysis was able to create a way to plot the strategic thinking of customers as it quantified subjective opinions. This revealed hidden motivations when purchasing and forced the respondents to assess the attributes individually according to their respective importance.

\subsection{Sampling}

A survey was used as the main tool for this research. The survey was designed with the aim of not just describing the sample, which will come from the sampling frame, but to describe the larger population. The proponent obtained historical data of previous jet fuel suppliers and other details that entails anything about their decision on the supplier. The interview was expected to yield the key attributes that influence the airlines' purchasing intention. The survey, applying conjoint analysis, consisted of a series of scenarios for respondents to assess. Each scenario was made up of combination of the focal jet fuel supplier attributes each of which are measured by two levels: high and low (pertaining to the importance of the given factor). A fractional factorial design was used by the researchers to yield the n number of scenario; fractional factorial design was specially selected to maximize the attributes explored and while minimizing the number of scenarios. The key attributes and their characteristics that will be used in this experiment will function as the independent variables. As for the dependent variables, the researchers examined the respondents' purchase intentions with regards to the jet fuel combinations described in each of the scenarios. The subjects were asked to order the eight profiles from most preferred to least preferred.

\subsection{Participants}

There are only a few fraction of personnel from fuel operations department who are able to answer the survey with credible background knowledge and over-all know how of the entirety fuel operations. The stratum selected by the researchers is personnel from the top-level management of the fuel operations department; these are usually the directors, managers, senior vice president of the fuel operations department and specialists for Jet-A1 fuel. A total number of ten (10) respondents were gathered by the researchers; three (3) from 
Philippine Airlines, six (6) from Cebu Pacific and one (1) from Air Asia. The researchers considered the potential respondents' background, responsibilities and how these may affect the survey results. The researchers determined the essential inclusion and exclusion criteria for the study population such that findings can accurately generalize or specify results to the target group rather than setting a target number of respondents.

\subsection{Development of Factors}

Price and availability are both the most recurring and constant factor from the selected pool of respondents for the research, as expected by the researchers from the related literature when it comes to vehicle purchasing intention. The researchers correlated the buying intentions of vehicle buyers to that of an airline's intention of buying oil. Both aforementioned factors, price and availability, were validated from the interviews performed by the researchers and in addition, other factors were also derived from the discussion. The survey was then developed from the exchange with the top level management of fuel operations for each airline.

F1. Lower prices for jet fuel are associated with more positive buying intention.

Buying jet fuel at a lower price compared to the competitors in the industry takes the interest of all the airlines. This is because any organization targets a cost-effective system for their company expenditures.

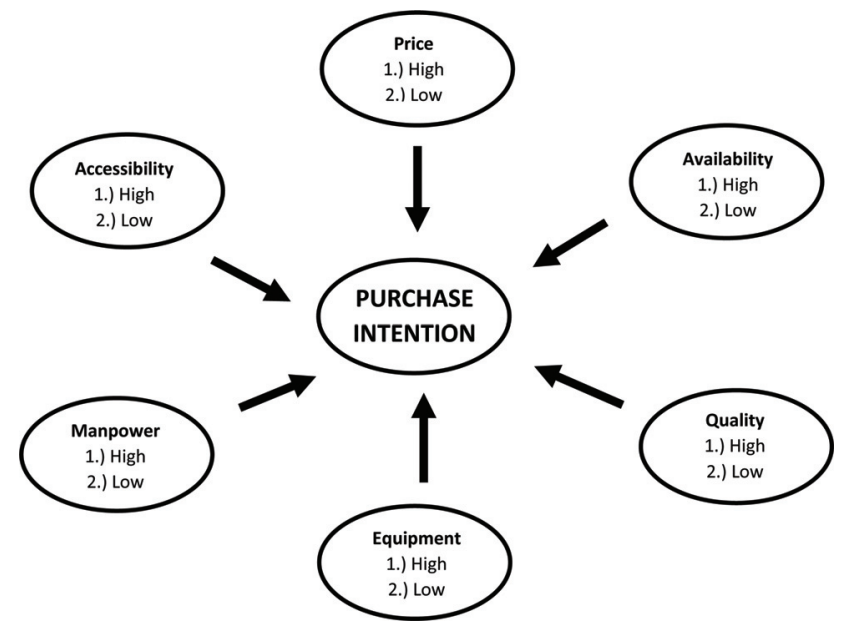

Figure 1 Factor development model. 
F2. A more available jet fuel is associated with more positive buying intention.

An airline cannot purchase Jet A-1 fuel if the oil company, either Shell, Petron or Caltex, cannot meet the airline's demand. The bigger the oil station and their capability to store larger number of oil, the more likely it is for them to purchase the fuel from the oil company.

F3. A more accessible jet fuel is associated with more positive buying intention.

Transportation fee is one of the fees that is included to the final price fuel and services that an oil company takes account of. The further the oil depot, the higher the transportation fee added to the price will be.

F4. Better equipped and able manpower that runs the aviation fuel company is associated with more positive buying intention.

An equipped and skilled workforce is directly proportional to servicing a quality fuel work from creating excellent Jet-A1 content down to the superior performance of transferring the fuel to its end-user (the airlines' airplanes). A capable staff entails the great ability to handle fuel superbly, as well.

F5. Better and advanced equipment is associated with more positive buying intention.

The instruments and devices used by the oil company in storing and maintaining the oil is a factor that airlines consider because of the effect it has on Jet-A1. Equipment and facilities that are not maintained and are little behind the technology advancements negatively influences the content and quality of the fuel itself. Therefore, the overall amenities and overhaul of the oil company is regarded as an important buying intention by air travel organizations.

F6. Fuel service that pass, if not exceeds, the quality standards that the air travel has is associated with more positive buying intention.

Air travel organizations have standards to be followed and an oil companies' oil content and other oil services needs to pass, if not exceed, the quality standards set by the airline. Fuel quality entails the oil content of JetA1 and overall performance of service of the companies such as Shell, Petron or Chevron.

\subsection{Variables}

The factors used in this research are based on the answers of the interview conducted by the researchers. The effects of price, availability, accessibility, manpower, equipment and fuel quality on purchase intention with regards to 
Table 1 Markov chain switching approach test for significance $(\mathrm{CI}=95 \%)$

\begin{tabular}{ll}
\hline Factors & Definition \\
\hline Price & $\begin{array}{l}\text { Final cost of fuel according to the oil company. } \\
\text { Available supply of oil that the oil company can provide; this is a } \\
\text { question of whether Shell, Petron and/or Chevron is able to meet the } \\
\text { fuel demand of an airline. }\end{array}$ \\
Accessibility & $\begin{array}{l}\text { The ease of access and convenience in attaining the Jet A-1. } \\
\text { Educational attainment and capabilities of the oil company's personnel } \\
\text { with regards to providing quality service; this also includes trainings } \\
\text { and seminars their staff has undergone. }\end{array}$ \\
Equipment & $\begin{array}{l}\text { Instruments and devices used by the oil company in storing and } \\
\text { maintaining the Jet A-1 fuel; their amenities and overhaul of the oil } \\
\text { company is also included in the factor's scope. }\end{array}$ \\
& $\begin{array}{l}\text { Whether the company's oil content and other fuel services pass the } \\
\text { quality standards of the air travel organization a propos fuel operations; } \\
\text { this factor includes the safety measures and/or the risk management } \\
\text { taken by the oil company with regards to fuel handling; this can also } \\
\text { mean the ability of the oil company to deliver aviation fuel on time. }\end{array}$ \\
\hline
\end{tabular}

Jet-A1 fuel were all assessed by asking the respondents to react to eight (8) scenarios with various combinations of stimuli. Table 1 gives a summary of the independent variables used in this experiment and their specific characteristic.

A survey using conjoint analysis provides a series of scenarios for respondents to consider. In this study, each scenario is made up of a combination of the six crucial fuel attributes, each of which is measured with two levels. If a full factorial design is used, and all possible combinations are presented, the respondents would have to consider 64 scenarios $(2 \times 2 \times 2 \times 2 \times 2 \times$ 2 or 26). The researchers decided to minimize the number of scenarios as a 64 scenario survey would be too large for a single respondent to evaluate. The scenarios were minimized to eight scenarios with different combinations of the stimuli that were used while still maintaining orthogonality among the levels. To achieve a smaller number of scenarios, the fractional factorial design is adopted so that not all possible combinations are used, but profiles are specially selected to maximize the attributes explored, while minimizing the number of profiles and thus this study adopted an orthogonal array design to construct the eight hypothetical Jet-A1 profiles as used in this study. Fractional factorial designs can be expressed by the formula Lk-p, in which:

- L: the number of levels of each attribute

- $\mathrm{k}$ : the number of factors investigated

- $\mathrm{p}$ : the size of the fraction of the full factorial used 
Table 2 Scenario combination (Card list)

\begin{tabular}{llll}
\hline Card ID & Price & Availability & Accessibility \\
\hline 1 & Low & Low & Low \\
2 & High & Low & High \\
3 & High & High & Low \\
4 & Low & Low & High \\
5 & High & High & High \\
6 & High & Low & Low \\
7 & Low & High & High \\
8 & Low & High & Low \\
\hline Card ID & Manpower & Equipment & Fuel Quality \\
\hline 1 & High & High & Low \\
2 & Low & High & Low \\
3 & High & Low & Low \\
4 & High & Low & High \\
5 & High & High & High \\
6 & Low & Low & High \\
7 & Low & Low & Low \\
8 & Low & High & High \\
\hline
\end{tabular}

In this study, we use $1 / 8$ of the full factorial design or 26-3. In the case of the combinations among these eight models, each attribute will have six values of High and Low values in order to create a balanced profile. Table 2 shows the eight distinctive scenarios created for this work, and the related combinations of attributes were used in the survey.

\section{Data and Results}

\subsection{Part-worth Scores}

A part-worth score or utility score was established for each attribute after generating the Conjoint Analysis Command Syntax, and it shows whether an attribute will add to a scenario's total worth or subtract from it. Most attributes had positive and higher scores if present or at a high level, and had negative or lower scores if absent or at a low level. Based on the results, it could thus be determined which of the attributes had the strongest influence on the choice of the respondents when deciding on which jet supplier to choose from.

Table 3 lists the utility scores for all six attributes. Price attribute had a score of -1.250 when low, and -2.500 when high, as this attribute had a reverse effect. Therefore, it can be said that the respondents were attracted to Oil Companies that offers lower prices. The second attribute (availability) 
24 K. I. S. Bassig et al.

Table 3 Utility scores of the attributes

\begin{tabular}{lccc}
\hline \multicolumn{3}{c}{ Utilities } \\
\hline Price & Utility Estimate & Std. Error \\
\hline \multirow{5}{*}{ Availability } & -1.250 & .050 \\
& High & -2.500 & .100 \\
& Low & 1.650 & .050 \\
& High & 3.300 & .100 \\
Manpower & Low & .800 & .050 \\
Equipment & High & 1.600 & .100 \\
& Low & .100 & .050 \\
Fuel Quality & Low & .200 & .100 \\
& High & .850 & .050 \\
& Low & 1.700 & .100 \\
(Constant) & High & 2.800 & .050 \\
\hline \multirow{6}{*}{ (Cow } & 5.600 & .100 \\
& & -2.925 & .185 \\
\hline
\end{tabular}

had a very high score of 3.300 when the Oil Company can provide the amount of Oil needed by the Airline Company, and a score of 1.650 when it can't. Thus, it can be stated that the respondents prefer a high level of Availability over a low level. The high level of Accessibility contributed a score of 1.600, while a low level of accessibility had an effect of .800. These results indicate that a high level of accessibility is preferred by the respondents. In terms of Manpower, the results showed a score of 0.200 with regard to high manpower, and .100 for low manpower. This indicates that the respondents prefer an Oil Company having a well-trained employees. With regard to equipment, these scored 1.700 when labeled as high and 0.850 when labeled as low. As a result, it can be said that a high level of equipment is preferred by the respondents. Lastly, the fuel quality attribute has a score of 2.800 when low, and 5.600 when high, it can be said that the respondents values the high quality of fuel that the Oil Companies offered. The part-worth utility scores all indicated that the respondents preferred a high level of availability,

Table 4 Utility scores of the attributes

\begin{tabular}{lr}
\hline \multicolumn{2}{c}{ Importance Values } \\
\hline Price & 20.371 \\
Availability & 18.894 \\
Accessibility & 10.060 \\
Manpower & 5.515 \\
Equipment & 10.941 \\
Fuel Quality & 34.219 \\
\hline
\end{tabular}




\section{Importance Score}

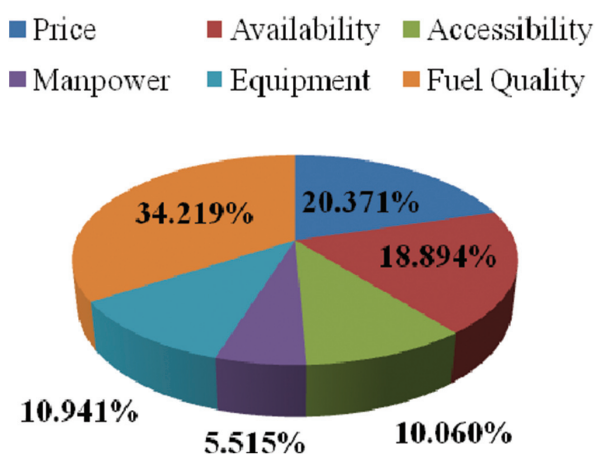

Figure 2 Average importance score.

accessibility, manpower, equipment, and a low level of price. Therefore, the premises from the factor development (3.5) established by the researchers, F1-F6, were supported.

While the study focuses on acquiring the utility scores of each attribute, the researchers applied conjoint analysis to calculate an averaged importance score out of a total of 100 . For instance, if an attribute is given a score of 50, this would mean that it contributed $50 \%$ to the outcome of the consumer's decision making. The tallied result from the initial survey is expected to correlate with the averaged importance score and yield a similar outcome.

\subsection{Discussion}

From conjoint analysis, the attributes developed has proven that a set of key attributes do affect decisions of airlines in choosing which oil company to opt for in terms of aviation fuel supply. The importance score presented in table 13

Table 5 Utility scores of the attributes

\begin{tabular}{lc}
\hline \multicolumn{2}{c}{ Importance Values } \\
\hline Fuel Quality & 34.219 \\
Price & 20.371 \\
Availability & 18.894 \\
Equipment & 10.941 \\
Accessibility & 10.06 \\
Manpower & 5.515 \\
\hline
\end{tabular}


confirms that these attributes hold a weight over the airlines' decision, thus supporting the purpose of the study.

\section{Conclusion}

This study identifies the key attributes of aviation fuel in local airlines operating in the Philippines. This study sought to measure a dependent variable, in this case purchase intention, toward eight scenarios with different combinations of the six main attributes. This conjoint approach allowed the respondents to consider more realistic situations and to take into account what they believe to be important. As a result, the outcomes of this study are able to show the relative importance of each attribute (i.e., the partworth utility score), rather than just a comprehensive preference ranking evaluation.

Using conjoint analysis, the researchers were able to identify the significant key attributes of jet fuel that heavily influences the purchasing intention of an airline. The above table shows the attributes and their respective importance score; the attributes are listed according to their importance with the first attribute having the heaviest importance weight and the last attribute having the least value of importance weight. The conjoint analysis conducted in this study investigates preferences for the jet fuel industry. Within conjoint analysis respondents rate the oil company's Jet-A1 services consisting of multiple attributes. Thus, in conjoint measurement, a respondent considers all factors concurrently for each attribute combination. Using this analysis, the user evaluations can be decomposed into separate utilities, or part-worths. Data collection is, therefore more holistic and more ecologically valid, because complete situations, rather than single features, are considered.

In this term, conjoint analyses provide an additional value to acceptance research since it is possible to obtain an accurate estimation of user tradeoffs between single device characteristics. Furthermore, it is possible to determine a valid model of consumer judgments. It is clear that some jet fuel characteristics are more relevant in the decision process of the airlines than others. Although the attribute price has the second heaviest importance weight among the other factors, compared to Table 8 , price had a negative value and actually had the lowest utility score. This means that consumers are willing to trade-off low price for services that had high level from any of the five attributes; when combined with other attributes and given a level as a complete scenario, consumers suddenly shift their purchasing intention for a more important attribute. 


\section{References}

[1] Acosta, L. A., Eugenio, E. A., Enano, N. H., Magcale-Macandog, D. B., Vega, B. A., Macandog, P. B. M., et al. (2014). Sustainability trade-offs in bioenergy development in the Philippines: an application of conjoint analysis. Biomass Bioener. 64, 20-41. doi: 10.1016/j.biombioe.2014.03.015

[2] Al-Othman, W. B. E., Lababidi, H. M. S., Alatiqi, I. M., and Al-Shayji, K. (2008). Supply chain optimization of petroleum organization under uncertainty in market demands and prices. Eur. J. Operat. Res. 189, 822-840. doi: 10.1016/j.ejor.2006.06.081

[3] Anthony, M. (1999). I Need to Know. Available at: http://drsmusic.com/ portal/PDFS/4133/i_need_to_know_piano.pdf

[4] Bahill, T. (2010). Systems and Industrial Engineering. Available at: http://www.sie.arizona.edu/sysengr/slides

[5] Beamon, B. (1999). Measuring supply chain performance. Int. J. Oper. Prod. Manag. 19, 275-292.

[6] Bendall-Lyon, D., and Power, T. L. (2004). The impact of structure and process attributes on satisfaction and behavioral intentions. J. Ser. Market. 18, 114-121.

[7] Bergkvist, L., and Rossiter, J. R. (2008). The role of ad likability in predicting ad's campaign performance. $J . A d v .37,58-97$.

[8] Chai, J., Liu, J. N. K., and Ngai, E. W. T. (2013). Application of decisionmaking techniques in supplier selection: a systematic review of literature. Exp. Syst. Appl. 40, 3872-3885. doi: 10.1016/j.eswa.2012.12.040

[9] Chand, A., Satyanarayana, K., and Plant, V. S. (2013). A study on e.r.p in visakhapatnam steel plant with advanced business application programming.

[10] Cheremisinoff, N., and Rosenfeld, P. (2009). "The petroleum industry," in Production-Best Practices in The Petroleum Industry, [online] doi: 10.1016/B978-0-8155-2035-1.10001-6

[11] Dabhilkar, M. (2011). Trade-offs in make-buy decisions. J. Purchas. Suppl. Manag. 17, 158-166. doi: 10.1016/j.pursup.2011.04.002

[12] Dickson, G. W. (1966). An analysis of vendor selection systems and decisions. J. Purchas. 2, 5-17.

[13] Egonsson, D. (2007). Preference and Information. Great Britain: Ashgate, 3-4.

[14] Ellram, L. M. (1990). The supplier selection decision in strategic partnerships. J. Purchas. Mater. Manag. 26, 8-14. 
[15] Fischer, G. W., Carmon, Z., Ariely, D., and Zauberman, G. (1999). Goalbased construction of preferences: task goals and the prominence effect. Manage. Sci. 45, 1057-1075.

[16] Fischer, G. W., and Hawkins, S. A. (1993). Strategy compatibility, scale compatibility, and the prominence effect. J. Exp. Psychol. Hum. Percept. Perform. 19, 580-597.

[17] Gensler, S., Hinz, O., Skiera, B., and Theysohn, S. (2012). Willingnessto-pay estimation with choice-based conjoint analysis: addressing extreme response behavior with individually adapted designs. Eur. J. Operat. Res. 219, 368-378. doi: 10.1016/j.ejor.2012.01.002

[18] Goldstein, W. M., and Einhorn, H. J. (1987). Expression theory and the preference reversal phenomena. Psychol. Rev. 94, 236-254.

[19] Eugene, H., (Gene) and Baker, P. III (1999). Design Making. Available at: http://www.unf.edu/ gbaker/Man6204/Decision.PDF

[20] Halme, M., and Kallio, M. (2014). Likelihood estimation of consumer preferences in choice-based conjoint analysis. Eur. J. Operat. Res. 239, 556-564. doi: 10.1016/j.ejor.2014.05.044

[21] Hsee, C. K. (1996). The evaluability hypothesis: an explanation for preference reversals between joint and separate evaluations of alternatives. Organ. Behav. Hum. Decisi. Process. 67 (3), 247-257.

[22] Huang, S. H., and Keskar, H. (2007). Comprehensive and configurable metrics for supplier selection. Int. J. Prod. Econ. 105, 510-523. Available at: http://www.sciencedirect.com/science/article/pii/S0925527 306001241

[23] Kahneman, D., and Tversky, A. (1979). Prospect theory: an analysis of decision making under risk. Econometrica 47, 18-36.

[24] Karniouchina, E. V., Moore, W. L., van der Rhee, B., and Verma, R. (2009). Issues in the use of ratings-based versus choice-based conjoint analysis in operations management research. Eur. J. Operat. Res. 197, 340-348. doi: 10.1016/j.ejor.2008.05.029

[25] Lee, J., and Kuo, J.-Y. (1998). Fuzzy decision making through trade-off analysis between criteria. Inform. Sci. 107, 107-126. doi: 10.1016/S0020-0255(97)10020-2

[26] Manzano, F. S. (2005). Supply Chain Practices in the Petroleum Downstream. Available at: http://hdl.handle.net/1721.1/33345

[27] Murray, J. G. (2009). Towards a common understanding of the differences between purchasing, procurement and commissioning in the UK public sector. J. Purchas. Suppl. Manag. 15, 198-202. doi: 10.1016/j.pursup.2009.03.003 
[28] Novemsky, N., Dhar, R., Schwarz, N., and Simonson, I. (2007). Preference fluency in choice. J. Market. Res. 44, 347-356.

[29] Nowlis, S. M., and Simonson, I. (1997). Attribute task comparability as a determinant of consumer preference reversals. J. Market. Res. 34, 205-218.

[30] Orme, B. K., Alpert, M. I., and Christensen, E. (1997). Assessing the Validity of Conjoint Analysis - Continued. Sawtooth Software Research Paper Series 1997. Available at: http:// www.sawtoothsoftware.com/ download/techpap/assess2.pdf [accessed February 21 2008].

[31] Patch, C. S., Tapsell, L. C., and Williams, P. G. (2005). Attitudes and intensions toward purchasing novel foods enriched with omega-3 fatty acids. J. Nutr. Educ. Behav. 37, 235-241.

[32] Roa, C. P., and Kiser, G. E. (1980). Educational buyer's perception of vendor attributes. J. Purchas. Mater. Manage. 16, 25-30.

[33] Robert Kreitner, A. K. (2009). Organizational behaviour. Available at: https://www.inkling.com/read/organizational-behavior-kreitner-kinicki10th/chapter-12/models-of-decision-making

[34] Sandor, Z., and Wedel, M. (2001). Designing conjoint choice experiments using managers' prior beliefs. J. Market. Res. 38, 430-444.

[35] Schonberger, R. (1986). World Class Manufacturing: The Lessons of Simplicity Applied. New York, NY: Free Press.

[36] Sinha, A. K., Aditya, H. K., Tiwari, M. K., and Chan, F. T. S. (2011). Agent oriented petroleum supply chain coordination: co-evolutionary Particle Swarm Optimization based approach. Exp. Syst. Appl. 38, 6132-6145. doi: 10.1016/j.eswa.2010.11.004

[37] Skinner, W. (1969). Manufacturing: missing link in corporate strategy. Har. Bus. Rev. 47, 136-145.

[38] Skinner, W. (1974). The focused factory. Har. Bus. Rev. 52, 113-120.

[39] Skinner, W. (1996). Manufacturing strategy on the 'S' curve. Prod. Operat. Manag. 5, 3-14.

[40] Stamm, C. L., and Golhar, D. Y. (1993). JIT purchasing attribute classification and literature review. Prod. Plann. Control 4, 273-282.

[41] Stephens, S. (2001). Supply Chain Council and Supply Chain Operations Reference (SCOR) Model Overview. Eagan, MN: Supply Chain Council, Inc.

[42] Tapping the Value in Spend Management. (n.d.).

[43] Tesseraux, I. (2004). Risk factors of jet fuel combustion products. Toxicol. Lett. 149, 295-300. 
[44] Tracey, M., and Neuhaus, R. (2013). Purchasing's role in global new product-process development projects. J. Purchas. Suppl. Manag. 19, 98-105. doi: 10.1016/j.pursup.2013.02.004

[45] Tversky, A. (2004). Preference, Belief, and Similarity: Selected Writings. Cambridge, MA: Massachusetts Institute of Technology, 1-2.

[46] Tversky, A., Sattath, S., and Slovic, P. (1988). Contingent weighting in judgment and choice. Psychol. Rev. 95, 371-384.

[47] Weaver, N. (1988). Petroleum. Available at: http://www.cabdirect.org/ abstracts/19882054101.html

[48] Weitz, B., and Wright, P. (1979). Retrospective self-insight on factors considered in product evaluations. J. Consum. Res. 6, 280-294.

[49] Wu, W. Y., Liao, Y. K., and Chatwuthikrai, A. (2014). Applying conjoint analysis to evaluate consumer preferences toward subcompact cars. Exp. Syst. Appl. 41, 2782-2792. doi: 10.1016/j.eswa.2013.10.011

[50] Yanoff, T. G., and Hansson, S. O. (2009). Preference Change. New York, NY: Springer.

[51] Philipine Department of Energy (2005). DOE Portal. Available at: https://www.doe.gov.ph/pep

\section{Biographies}

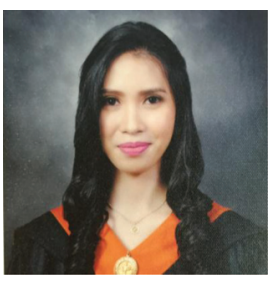

K. I. S. Bassig received her degree in Bachelor of Science in Industrial Engineering from Adamson University, Manila, Philippines in the year 2015. After interning under the Kaizen department for Toyota Motors Corporation, Philippines, Karla pursued a career as a business process analyst in SPi Global where she handles and monitors accounts' effectiveness and efficiency in terms of output, delivery and profitability. She is currently in training for a green belt in Lean Six Sigma and is working to complete her six sigma project. Aside from being an analyst, Karla aspires to receive a master's degree and build a life's work in business development with the use of her growing background in communications, project management, strategic planning and continuous improvement. 


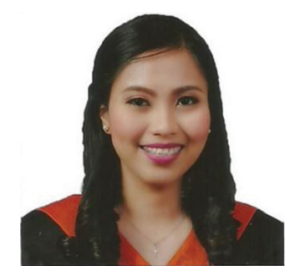

H. A. Silverio works as a Policy Analyst under Business Systems Division with a specialization in the development, maintenance and recommendation of improvements to processes, policies and procedures at Metropolitan Bank and Trust Company (MBTC), known as the strongest Bank in the Philippines. She is interested in pursuing a career in Business Process Re-engineering as it offers opportunity for in-depth application of re-engineering methodologies and principle to conduct process modernization.

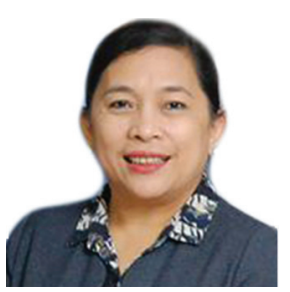

V. C. Quevedo earned her Ph.D. Degree in Educational Evaluation and Research and M.S. in Industrial Engineering Major in Operations Research at the University of the Philippines - Diliman. She serves as the Vice President for Administrative Affairs and an Associate Professor of the Industrial Engineering Department of Adamson University. 
